\title{
THE STRESS-STRAIN STATE OF HORIZONTAL JOINTS OF WALL PANELS
}

\author{
Anatolii KOSTYUK, Dariya KOVTUNENKO, Aleksei KOVTUNENKO
}

\begin{abstract}
The article is devoted to the experimental and numerical research of the stress-strain state of wall panels joints from foam concrete of natural hardening. The eccentricity of the load and the quantity of indirect reinforcement meshes are adopted as factors that have a significant effect on the stress-strain state of the joint elements. The load in the experimental research and numerical simulation was applied in steps of 0.1 of the estimated value of the destructive force. Numerical modelling was carried out with consideration of the physical nonlinearity of the wall panel materials. A significant increment in the displacement of the design scheme nodes at the current loading stage was taken as a destruction criterion in numerical modelling. It is noted that the installation of indirect reinforcement meshes leads to a reduction of transverse deformations of the wall panel, but does not significantly affect the bearing capacity of the joint.
\end{abstract}

Keywords: eccentricity; foam concrete of natural hardening; horizontal joints; indirect reinforcement; stress-strain state; wall panel

\section{STATE OF THE MATTER}

The foam concrete is widely used in modern construction. It is possible to achieve high thermal performance in enclosing structures due to its structure. The production and use of large wall panels of foam concrete for low-rise construction will shorten the time of construction and installation works and allow to receive housing which will be comfortable at any time of the year.

There are several design solutions for joints (Fig. 1), consisting of wall panels and overlapping plates, which can be divided into contact (Fig. 1a), platform (Fig. 1b, c) and combined (contact-platform) (Fig. 1d, e) joints. A feature of the last type of joints is the presence of both a platform and a contact part. Joints of wall panels are designed with one- and two-sided arrangements of slabs (Fig. 1c, e).
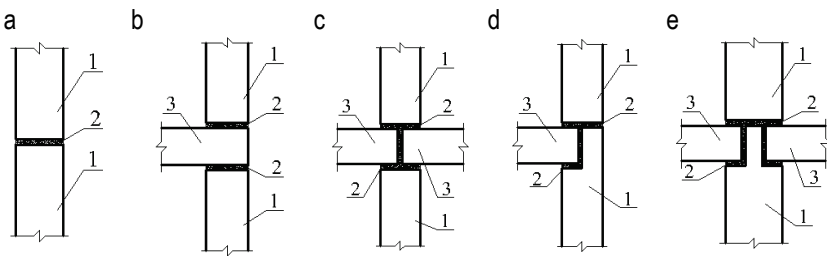

Figure 1 Designs of wall panels joints:

a, b, d, - joint of external walls; a, c, d - joint of internal walls; a - contact joint; b, c platform joint; $d, e,-$ combined joints; $b, d$ - joints with one-sided support of the slab; c, e - joints with two-sided support of slabs.

The transfer of vertical forces in horizontal joints between panels represents the most difficult task of largepanel construction. The studies listed below concern the analysis of the support zone strength of panels made of heavy or light concrete from various factors, as well as the stressstrain state of the joint as a whole.

The research of butt joints in buildings from large panels was carried out since the 1930s by Soviet and European scientists. Among them, the works of [2-5, 7-16] and many others should be noted. All these works are devoted to the stress-strain state in the wall panels, under the influence of a certain set of factors affecting it. However, each of the works examines only one of the joint types and does not cover the simultaneous effect of the load application eccentricity and the presence of indirect reinforcement.

The aim of the work is to study the stress-strain state of three variants of butt joints of wall panels made of foam concrete of natural hardening.

The following tasks were accomplished to achieve this goal:

1. Experimental research of combined joint,

2. Analysis of experimental results,

3. Numerical simulation using a software package,

4. Comparison of the results of two experiments.

\section{EXPERIMENTAL RESEARCH}

The authors of this article carried out experimental research of combined joints of wall panels taking into consideration two important factors: the eccentricity of the load application and the amount of indirect reinforcement. The combined joint design was chosen as the main one because it includes a contact and a platform parts. This feature allows studying simultaneously three types of joint design.

The samples for the experimental research were made consisting of three parts (Fig. 2):

1. Overlying panel

2. Underlying panel

3. Floor slab

The dimensions of the sample elements are taken along the geometrical similarity to the actual parameters of the panels and their joints. The thickness of the wall panels is $200 \mathrm{~mm}$ (100 mm contact part and $100 \mathrm{~mm}$ platform part). The thickness of the floor slab is $150 \mathrm{~mm}$. The width of the samples was adopted $600 \mathrm{~mm}$ with consideration of the press bearing pad dimensions. Supporting areas in the contact and platform parts of the sample overlying wall panel are located close to each other, so it can be assumed that the load on the sample is applied to its entire width $l_{\mathrm{c}}=200 \mathrm{~mm}$. The height of the overlying panel is assumed to be $3 l_{\mathrm{c}}=600 \mathrm{~mm}$. The 
maximum possible support width in the platform part of the underlying panel is $100 \mathrm{~mm}$. The required height of the underlying panel is $3 l_{\mathrm{c}}=300 \mathrm{~mm}$. The ledge height of the underlying panel is $160 \mathrm{~mm}$. Finally, the height of the underlying panel together with the ledge is $600 \mathrm{~mm}$, based on the production conditions. The cantilever ledge of the floor slab fragment is $510 \mathrm{~mm}$.

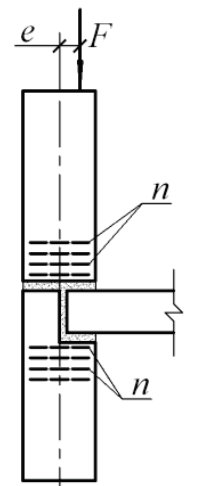

Figure 2 Construction of experimental samples:

a -factors considered in the experiment; $b$ - layout of the joint elements; 1 - overlying panel; 2 - underlying panel; 3 -floor slab; $1 \mathrm{~A}$ - the inner surface of the overlying panel; $1 \mathrm{~B}$ - the outer surface of the overlying panel; $2 \mathrm{~A}$ - the inner surface of the underlying panel; $2 \mathrm{~B}$ - the outer surface of the underlying panel.

The wall panels of test samples are made of natural hardening foam concrete with density from 700 to $1000 \mathrm{~kg} / \mathrm{m}^{3}$. The slab is made of heavy concrete of class C 25/30. The indirect reinforcement of the wall panels is made of reinforcing wire mesh $\varnothing 3 \mathrm{~mm}$ class Bp-I with a characteristic yield strength $f_{y}=608 \mathrm{MPa}$ and modulus of elasticity $E=30.51 \times 10^{5} \mathrm{MPa}$.

By analysis of the experiment results it is concluded that indirect reinforcement prevents the formation and development of a vertical crack from cement mortar joint between wall panels. At the same time, the bearing capacity of the sample as a whole does not change.

The increasing of loads eccentricity towards the platform part leads to decreasing of the contact area of the panels in the contact part (formation of the horizontal crack in the cement mortar) and redistribution of load onto the platform part. As a result, the destruction of the joint occurs along the platform part.

More detailed results of experimental research of the stress-strain state of the wall panels support zones with the identification of the most probable destruction schemes are given in [6].

\section{NUMERICAL SIMULATION}

In addition to the experimental tests, the authors carried out a numerical research of the stress-strain state of the support zones of wall panels. The software package Lira 9.4 that implements the finite element method was used for that purpose.

The following finite elements that allow the construction of a flat model were used at modelling:
1. Physically nonlinear universal rectangular finite element of a flat problem (beam-wall) (No. 223) was used for modelling of the body of a foam concrete panels, heavy concrete floor slab and cement mortar.

2. Physically nonlinear universal spatial rod finite element (No. 210) was used for modelling of meshes of indirect reinforcement.

The analysis was made taking into consideration nonlinear properties of the materials with a stepwise increment of the load. The physical nonlinearity of the material was taken into account by the " $\sigma-\varepsilon$ " diagram, which has an exponential dependence. The design values of mechanical properties of the materials were determined from the results of experimental compression tests of cube and prism samples, as well as tension tests of reinforcing bars. A significant increment of the design scheme nodes displacement at the current load stage was assumed as a criterion of the joints destruction.

The counter plots of the principal stresses distribution (Fig. 3) can be represented as a result of the joint samples analysis by software package Lira PC.

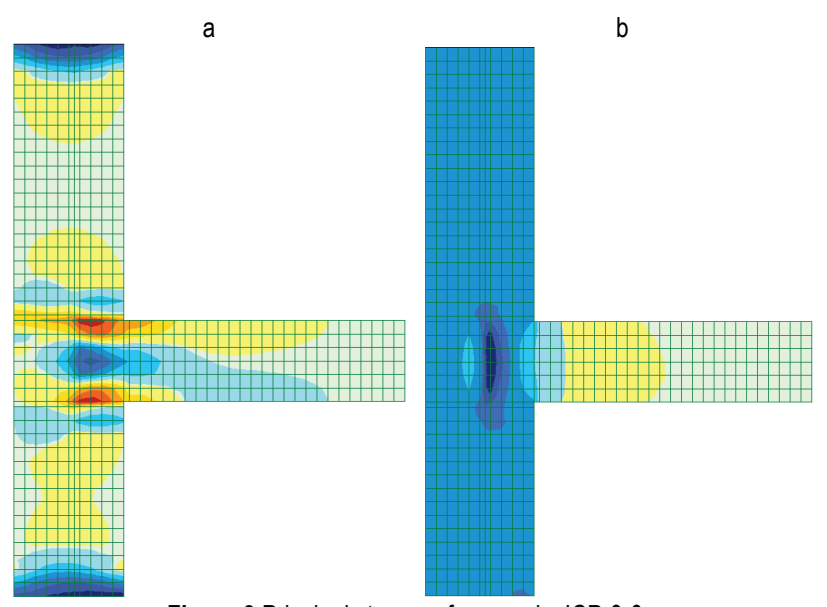

Figure 3 Principal stresses for sample JCP-0-0: a - principal stresses $\sigma_{1} ; b$ - principal stresses $\sigma_{3}$

According to the counter plots of the principal stresses (Fig. 3), the support zones of the wall panels are in the condition of biaxial compression, which determines the nature of failure observed in the experimental research.

The dependences of the relative deformations on the load level (Fig. 4) are plotted to compare the results of a numerical study with the experimental research.

Statistical analysis (Tab. 1) of results comparison of samples numerical modelling and experimental research showed that the accepted model in SP "LIRA" describes the stress-strain state of joints of wall panels from natural hardening foam concrete with sufficient accuracy.

A numerical experiment was planned and carried out to generalize the results of the experimental research of the wall panel joint samples. The three types of horizontal joints of wall panels from natural hardening foam concrete with a stepwise increase of load up to the limit value were provided by the experiment plan. 


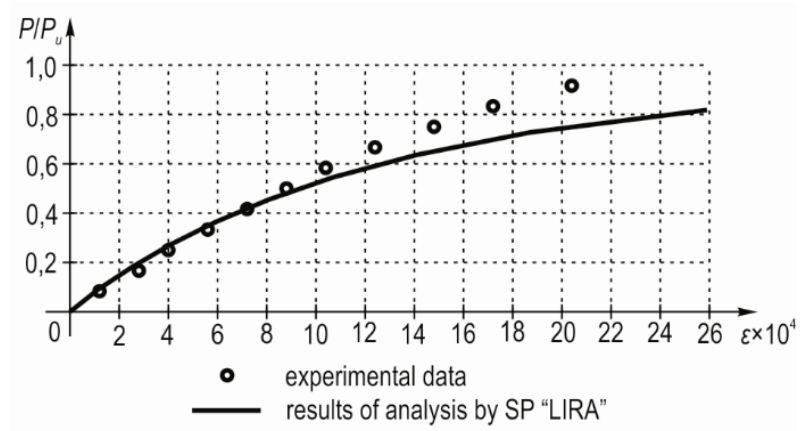

Figure 4 Diagram of the strain dependence on the load level for inner surface of overlying panel of the sample JCP 2-20 (1).

Table 1 Comparison of bearing capacity of combined horizontal joints

\begin{tabular}{|l|c|c|c|c|}
\hline & Cubic & \multicolumn{3}{|c|}{ Bearing capacity of joint, $\mathrm{kN}$} \\
\cline { 3 - 5 } Sample code & $\begin{array}{c}\text { strength } \\
f_{\text {cd,cube, }} \\
\text { MPa }\end{array}$ & $\begin{array}{c}\text { by test } \\
\text { results } \\
F_{\text {exp }}\end{array}$ & $\begin{array}{c}\text { based on the results } \\
\text { of numerical studies } \\
F_{\text {teor }}\end{array}$ & $F_{\text {exp }} / F_{\text {teor }}$ \\
\hline JCP-0-0 & 2.39 & 60.00 & 53.33 & 1.12 \\
\hline JCP -2-0 & 0.89 & 33.33 & 20.00 & 1.67 \\
\hline JCP -4-0 & 1.99 & 46.67 & 53.33 & 0.87 \\
\hline JCP -0-20 & 1.42 & 33.33 & 26.67 & 1.25 \\
\hline JCP -2-20-1 & 2.95 & 73.33 & 66.67 & 1.1 \\
\hline JCP -2-20-2 & 2.84 & 46.67 & 40.00 & 1.17 \\
\hline JCP -2-20-3 & 4.16 & 86.67 & 80.00 & 1.08 \\
\hline JCP -4-20 & 3.26 & 46.67 & 53.33 & 0.87 \\
\hline JCP -0-40 & 2.14 & 33.33 & 46.67 & 0.71 \\
\hline JCP -2-40 & 1.66 & 53.33 & 40.00 & 1.33 \\
\hline JCP -4-40 & 4.61 & 73.33 & 80.00 & 0.92 \\
\hline
\end{tabular}

The physical and mechanical characteristics of the materials obtained during the experimental research were used. The averaged data for all the necessary parameters were used at planning a numerical experiment. The identical characteristics of the materials for all models of wall panel horizontal joints were used to obtain the objective results for comparison.

The following physical and mechanical material characteristics were used at modelling:

1. For foam concrete of wall panels:

- Density $-8 \mathrm{kN} / \mathrm{m}^{3}$

- Modulus of elasticity $\left(E_{0}\right)-2902769 \mathrm{kN} / \mathrm{m}^{2}$

- Ultimate value of tensile stresses $\sigma(+)=309.8901 \mathrm{kN} / \mathrm{m}^{2}$

- Ultimate value of the compressive stresses $\sigma(-)=2402.629 \mathrm{kN} / \mathrm{m}^{2}$

2. For heavy concrete of floor slab:

- Density - $25 \mathrm{kN} / \mathrm{m}^{3}$

- Modulus of elasticity $\left(E_{0}\right)-24026290 \mathrm{kN} / \mathrm{m}^{2}$

- Ultimate value of tensile stresses $\sigma(+)=1402.351 \mathrm{kN} / \mathrm{m}^{2}$;

- Ultimate value of the compressive stresses $\sigma(-)=15004.17 \mathrm{kN} / \mathrm{m}^{2}$.

3. For cement mortar of joint

- Density - $15 \mathrm{kN} / \mathrm{m}^{3}$

- Modulus of elasticity $\left(E_{0}\right)-11473780 \mathrm{kN} / \mathrm{m}^{2}$

- Ultimate value of tensile stresses $\sigma(+)=550.1531 \mathrm{kN} / \mathrm{m}^{2}$
- Ultimate value of the compressive stresses $\sigma(-)=3500.974 \mathrm{kN} / \mathrm{m}^{2}$

4. For wire rods of reinforcement meshes:

- Density - $78.5 \mathrm{kN} / \mathrm{m}^{3}$

- Modulus of elasticity $\left(E_{0}\right)-2 \times 10^{8} \mathrm{kN} / \mathrm{m}^{2}$

- Diameter - $3 \mathrm{~mm}$

The loads distributed by linearly dependent were applied in stages by steps of 0.1 of the assumed destructive load.

With the purpose of creating a mathematical model of the corresponding physical work of the wall panels joint, the loads were transferred to the joint through a rigid bar with following characteristics:

- Density - $1 \times 10^{5} \mathrm{kN} / \mathrm{m}^{3}$;

- Modulus of elasticity $\left(E_{0}\right)-2902770 \mathrm{kN} / \mathrm{m}^{2}$;

Dependency diagrams of longitudinal and transverse deformations in wall panels on the load are plotted (Fig. 514) based on the numerical models analysis results of the wall panels horizontal joints.

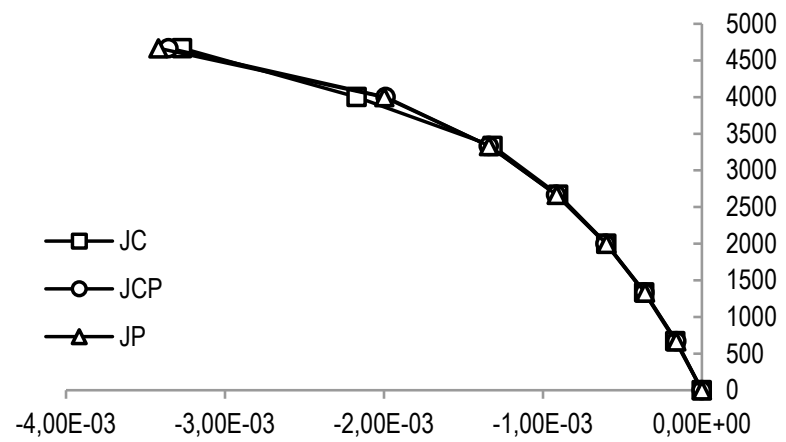

Figure 5 Diagrams of the strain dependence on the applied load for inner surface of overlying panel of samples with two meshes of indirect reinforcement and with eccentricity equal to $20 \mathrm{~mm}$.

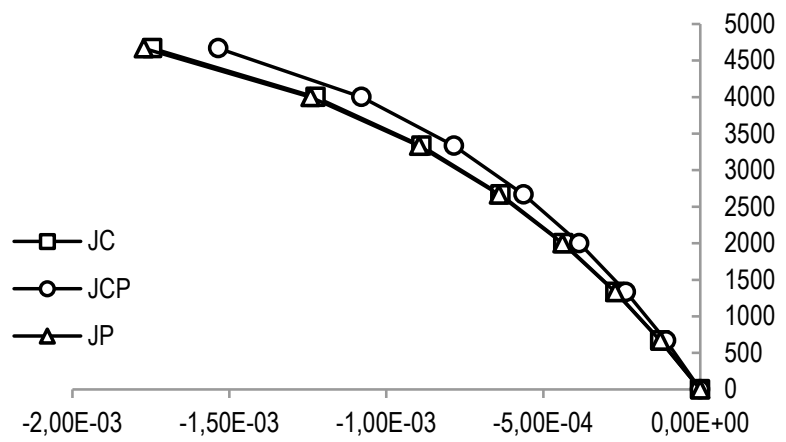

Figure 6 Diagrams of the strain dependence on the applied load for inner surface of underlying panel of samples with two meshes of indirect reinforcement and with eccentricity equal to $20 \mathrm{~mm}$. 


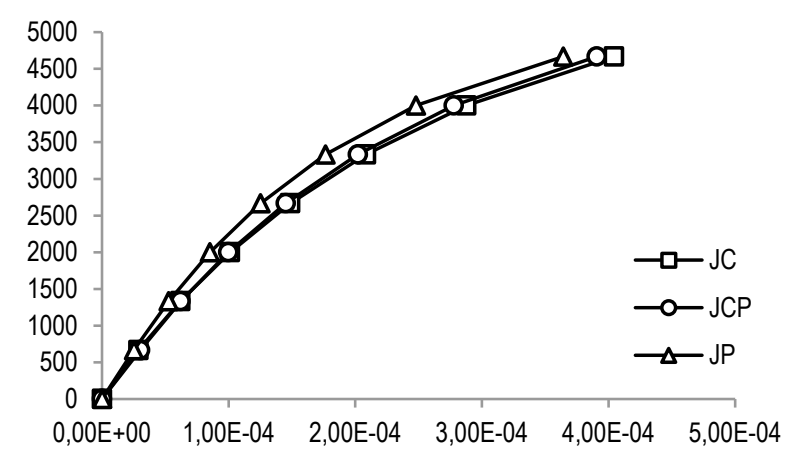

Figure 7 Diagrams of the transverse strain dependence on the applied load for section of overlying panel on distance of $20 \mathrm{~mm}$ from cement mortar of samples with two meshes of indirect reinforcement and with eccentricity equal to $20 \mathrm{~mm}$.

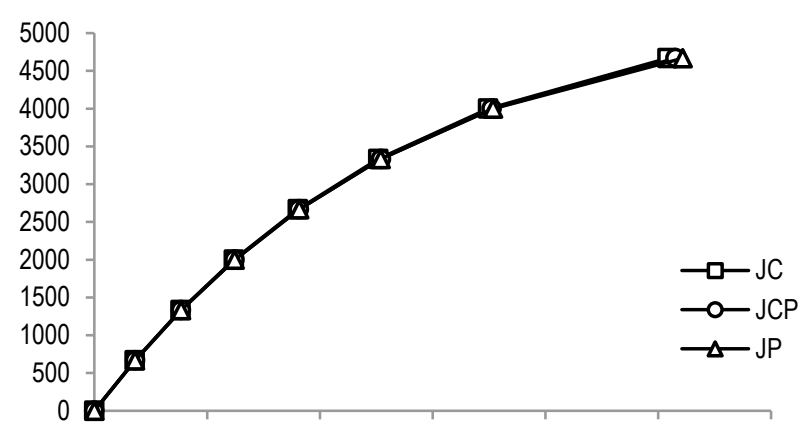

0,00E+00 1,00E-04 2,00E-04 3,00E-04 4,00E-04 5,00E-04 6,00E-04

Figure 8 Diagrams of the transverse strain dependence on the applied load for the section of overlying panel on distance of $170 \mathrm{~mm}$ from cement mortar of samples with two meshes of indirect reinforcement and with eccentricity equal to $20 \mathrm{~mm}$.

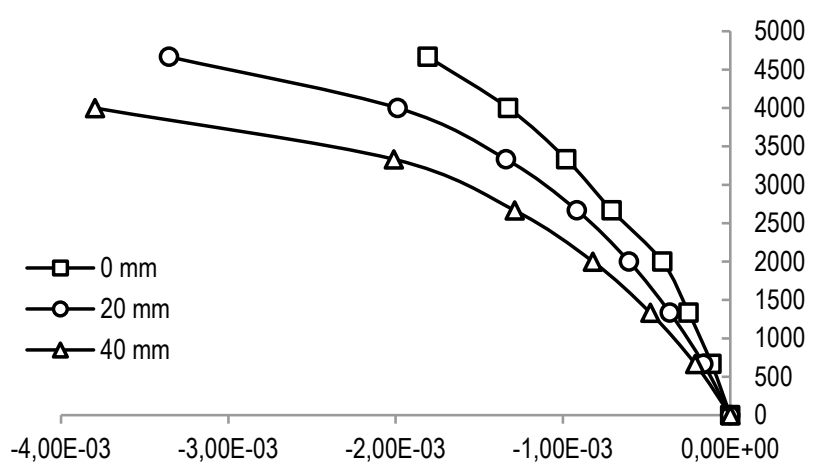

Figure 9 Diagrams of the strain dependence on the applied load for inner surface of overlying panel of combined design samples with two meshes of indirect reinforcement

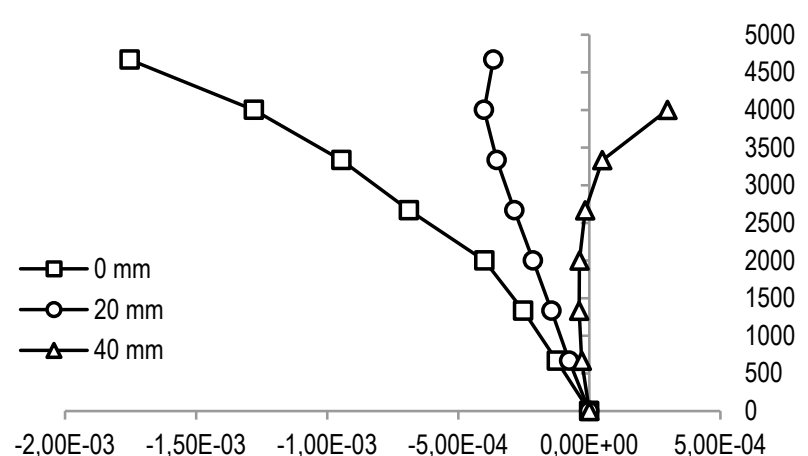

Figure 10 Diagrams of the strain dependence on the applied load for outer surface of overlying panel of combined design samples with two meshes of indirect reinforcement

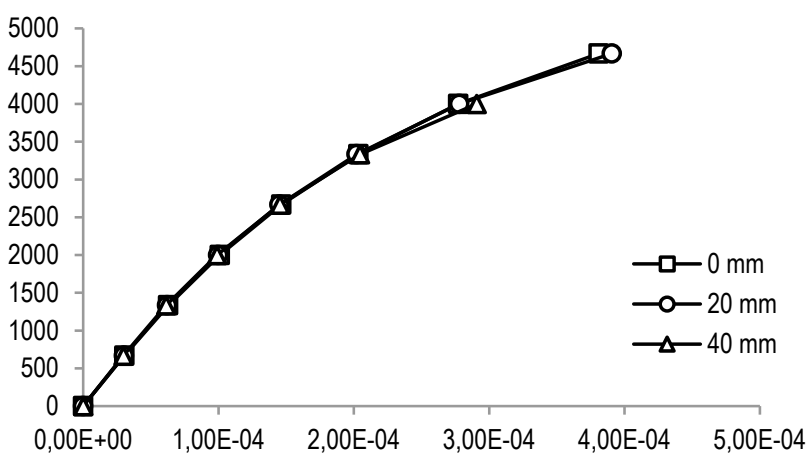

Figure 11 Diagrams of the transverse strain dependence on the applied load for the section of overlying panel on distance of $20 \mathrm{~mm}$ from cement mortar of combined design samples with two meshes of indirect reinforcement.

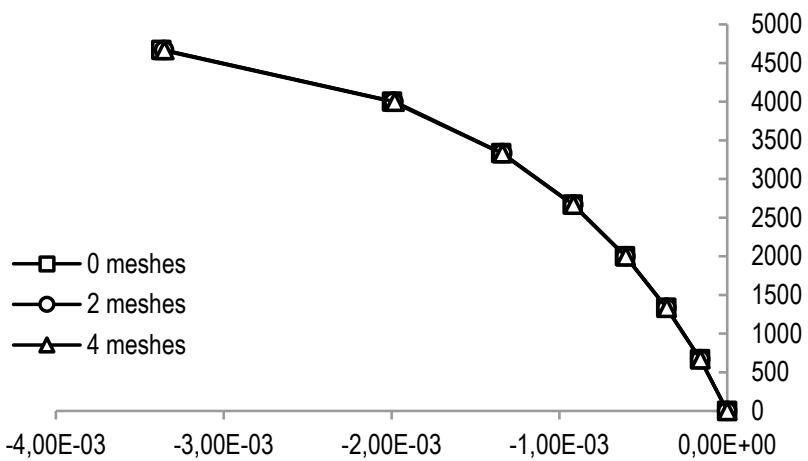

Figure 12 Diagrams of the strain dependence on the applied load for inner surface of overlying panel of combined design samples with eccentricity equal to $20 \mathrm{~mm}$

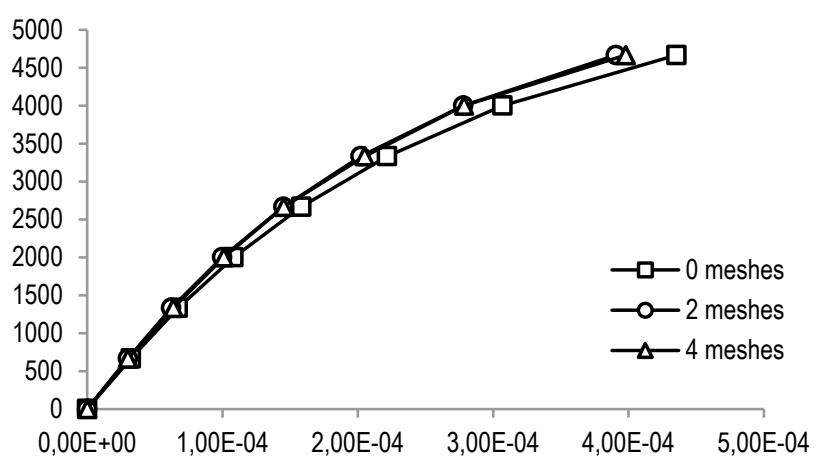

Figure 13 Diagrams of the transverse strain dependence on the applied load for the section of overlying panel on distance of $20 \mathrm{~mm}$ from cement mortar of combined design samples with eccentricity equal to $20 \mathrm{~mm}$.

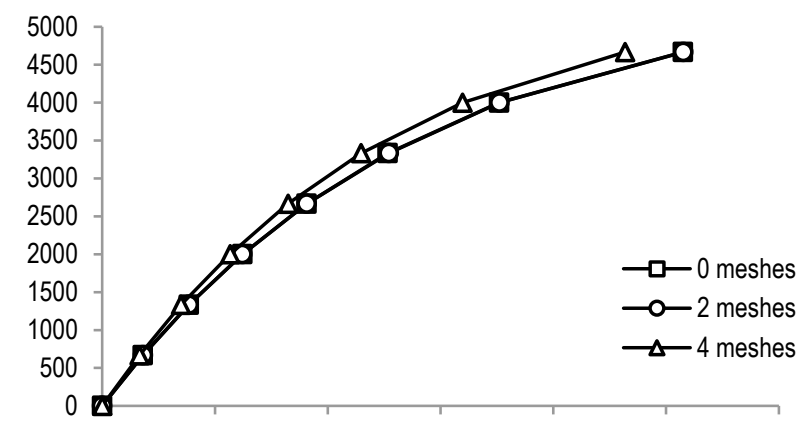

0,00E+00 1,00E-04 2,00E-04 3,00E-04 4,00E-04 5,00E-04 6,00E-04

Figure 14 Diagrams of the transverse strain dependence on the applied load for the section of underlying panel on distance of $20 \mathrm{~mm}$ from cement mortar of combined design samples with eccentricity equal to $20 \mathrm{~mm}$. 


\section{CONCLUSION}

The following conclusions can be made by analysing the obtained diagrams:

1. The longitudinal deformations are reduced by $12 \%$ on the outer surface of the bottom panel and increased by an average of $10 \%$ on the inner surface as the result of redistribution of internal forces into a more rigid platform part of the combined joint.

2. The design of the platform joints of the wall panels provides greater stiffness of the joint in the direction transverse to the axis of the wall panels, and as a result, the transverse deformations in the support part $(h \leq 0.5 \mathrm{~b})$ of the wall panel are reduced by $13-17 \%$.

3. The wall panel horizontal joints design does not exert any influence on the overall bearing capacity of joints.

4. The installation of the indirect reinforcement meshes resulted in the reduction of transverse deformations in the support zone of the wall panels by $8-12 \%$ in all the three types of joint design.

5. The installation of the indirect reinforcement meshes does not affect longitudinal deformations in the body of the wall panels and the bearing capacity of the horizontal joints as a whole.

6. Increasing of loads eccentricity towards the inner surface of the wall panels leads to an increase of the compression deformation on the inner surface of the overlying panel and the outer surface of the underlying panel. As a result, the compression deformation on the opposite sides of the wall panels is decreasing up to the emergence of tensile deformation on the outer side of the overlying panel.

7. The transverse deformations increase to $5 \%$ in the underlying panel and up to $20 \%$ in the overlying panel with increasing eccentricity. The effect of the eccentricity decreases as the considered cross-section is removed from the place where the load is applied.

8. The loads preceding the development of plastic deformations decrease from $0.5 P_{u}$ (for the sample without eccentricity) to $0.33 P_{u}$ (for the sample with eccentricity equal to $40 \mathrm{~mm}$ ).

9. The bearing capacity of the horizontal joints of the wall panels decreases by $12.5 \%$ for joints where $e=20 \mathrm{~mm}$, and by $25 \%$ for samples where $e=40 \mathrm{~mm}$ with increasing eccentricity.

\section{REFERENCES}

[1] Barboza, A. d S. R. \& El Debs, M. K. (2006). Load-bearing capacity of mortar joints between precast elements. Magazine of Concrete Research, 58(9), 589-599. https://doi.org/10.1680/macr.2006.58.9.589

[2] Grasser, F. \& Daschner, F. (1972). Die Druckfestigkeit von Mörtel fugenzwischen Beton Fertigteilen. Deutscher Ausschuss für Stahlbeton, 221-228.

[3] Drozdov, P. F., Gorshkov, Yu. K., \& Panshin, L. L. (1975). Compressed mortar joints. Housing construction, 6, 9-10.

[4] Gorachek, E. \& Lishak, I. (1980). Strength and rigidity of butt joints of panel structures. Moscow, stroiizdat, 191-199.

[5] Korchagin, O. P. (1986). The ultimate condition of large-panel buildings caused by the thawing of mortar joints. Work of constructions of residential buildings from large-sized elements: a collection of scientific works. Central Research Institute of Housing, 104-106.

[6] Kostyuk, A. \& Kovtunenko, D. (2016). Experimental research of combined joints of wallboards from natural hardening foam concrete. Technical Journal, 10(3-4), 124-127.

[7] Kotov, I. T. (1968). Investigations of the influence of the assembly seam on the strength of panel walls. Durability of large-panel structures. 100-106.

[8] Lishak, V. I. \& Agranovsky, V. D. (1984). Influence of thickness and strength of solution joints on the bearing capacity of horizontal joints. Constructive systems of fullassembled residential buildings: a collection of scientific papers. Central Research Institute of Building Constructions, 106-111.

[9] Morozov, Yu. B. \& Sedlovets, G. F. (1971). Investigation of strength and deformations of horizontal joints of wall panels. Investigation of strength and calculation of multi-storey buildings. MNIITEP Moscow, Russia.

[10] Sokolov, B. S. \& Nikitin, G. P. (2007). Perfection of the procedure for calculating combined joints of building panels. Bulletin of Tomsk State Architectural and Construction University, 1, 81-90.

[11] Sedov, A. N. (2009). Structural and technological features of reinforcement of combined joints in large-panel buildings during reconstruction. Author's abstract. Thesis for a scientific degree PhD. KazGASU Kazan, Russia.

[12] Sementsov, S. A. (1961). Strength of knots of interface of walls and ceilings in large-panel buildings. Concrete and Reinforced Concrete, 1, 14-18.

[13] Sokolov, B. S. (1992). A new approach to calculating the strength of concrete elements under local load action. Concrete and Reinforced Concrete, 10, 22-25.

[14] Spiridonov, V. V. (1957). Bearing capacity of horizontal joints of large-panel buildings. Concrete and Reinforced Concrete, 5 , 199-202.

[15] Spiridonov, V. V. (1957). Bearing capacity of horizontal joints of large-panel buildings. Concrete and Reinforced Concrete, 5 , 199-202.

[16] Shapiro, G. I. \& Shapiro, A. G. (2008). Calculation of the strength of platform joints of panel buildings. Industrial and Civil Construction, 1, 55-57.

\section{Authors' contacts:}

Anatolii KOSTYUK, Professor

Odessa State Academy of Civil Engineering and Architecture

Address: Ukraine, Odessa, Didrikhsona St., 4

Tel./Fax,e-mail: +380 505523 855, isi@ogasa.org.ua

Dariya KOVTUNENKO, Assistant

Odessa State Academy of Civil Engineering and Architecture

Address: Ukraine, Odessa, Didrikhsona St., 4

Tel./Fax,e-mail: +380 673655 520, kovtunenko.d.o@gmail.com

Aleksei KOVTUNENKO, Assistant Professor

Odessa State Academy of Civil Engineering and Architecture

Address: Ukraine, Odessa, Didrikhsona St., 4

Tel./Fax,e-mail: +380 963960 557, kovtunenko.aleksei.od@gmail.com 